\title{
Quantitative Evaluation of the Abrasion Rate in Attrition Washing on Lead Contaminated Soil from Shooting Ranges
}

\author{
Chiharu Tokoro*1, Yutaro Yamaoka*2, Sei Yuki*2, Tomohiro Shiozawa*2 and Shuji Owada \\ Department of Resources and Environmental Engineering, School of Creative Science and Engineering, \\ Faculty of Science and Engineering, Waseda University, Tokyo 169-8555, Japan
}

The effects of attrition on sandy and silty Pb-contaminated soil from shooting ranges were quantitatively investigated. The abrasion rate could be quantitatively evaluated using a population balance model from the size distribution of soil particles before and after attrition in an intensive mixer. The maximum abrasion rate was $0.047 \mu \mathrm{m} / \mathrm{s}$ in the first stage of attrition ( 1 min of grinding), and then declined between 2 and 4 min of grinding. The two samples had similar maximum abrasion rates, but the decline in the abrasion rate was larger in the silty soil, which would have a thinner soft layer on the surface of the soil particles, than the sandy soil. The incremental change in the mass fraction of $\mathrm{Pb}$ in the $<20 \mu \mathrm{m}$ particle size fraction increased proportionally with the abrasion thickness from the surface of the soil particles. Although the Japanese regulatory standard for the $\mathrm{Pb}$ concentration in soil $(150 \mathrm{mg} / \mathrm{kg}$ ) was not met for either sample, the Japanese regulatory standard for the concentration of leached $\mathrm{Pb}(0.01 \mathrm{mg} / \mathrm{L})$ was met for silty soil after attrition. Sequential extraction using Tessier's procedure for the $>20 \mu \mathrm{m}$ size fraction before and after attrition showed the attrition was more effective for the oxides or organic-bound species and carbonate species of $\mathrm{Pb}$ chemical forms. [doi:10.2320/matertrans.M2012240]

(Received July 4, 2012; Accepted August 29, 2012; Published October 11, 2012)

Keywords: abrasion rate, attrition, lead contamination, stirrer mill, soil washing, population balance model

\section{Introduction}

The decontamination and remediation of contaminated soils has become more important in Japan, especially after the enforcement of the Soil Contamination Countermeasures Law in 2003. ${ }^{1,2)}$ Heavy metal contamination to soil exists at many industrial and mining sites throughout the world. Lead $(\mathrm{Pb})$ is one of the most frequently encountered contaminants in soil. ${ }^{3-5)}$ Spent pellets from shooters at shooting ranges have resulted in severe $\mathrm{Pb}$ contamination of soil., ${ }^{6,7)}$ Several sites where the $\mathrm{Pb}$ concentration exceeds $10,000 \mathrm{mg} / \mathrm{kg}$ have been reported. ${ }^{8,9)} \mathrm{Pb}$ contamination in soils has the potential to cause a variety of environmental problems in plants, animals and humans. ${ }^{10-12)}$ For example, lead poisoning caused by ingestion of pellets has been reported in whooper swans and tundra swans. ${ }^{14,15)}$

Soil washing is an ex situ soil remediation technology that is based on mineral processing techniques such as grinding and sieving. ${ }^{16-18)}$ Most organic or inorganic contaminants tend to bind, either chemically or physically, to clay, silt, and organic soil particles, which are generally attached to sand or gravel particles by physical processes such as compaction and adhesion. ${ }^{19)}$ Reduction of soil contamination then occurs through particle size separation. In the soil washing processes, fine clay or silt particles are washed and separated from the coarser sand or gravel soil particles, and the contaminants are concentrated into a smaller volume of soil mainly consisting of fine particles that can be disposed of. However, a shortage of landfill sites for disposal means that more efficient washing and reduction of the quantity of contaminated soil are required.

When a spent pellet is released in the soil, its metallic $\mathrm{Pb}$ surface is gradually oxidized to $\mathrm{PbO}$ and subsequently transformed into carbonate phases such as $\mathrm{PbCO}_{3}$. In

\footnotetext{
${ }^{* 1}$ Corresponding author, E-mail: tokoro@waseda.jp

${ }^{* 2}$ Graduate Student, Waseda university
}

contaminated soils under aerobic conditions, $\mathrm{Pb}$ is often advected as carbonate- or phosphate-bound phases. ${ }^{9,20,21)}$ If these $\mathrm{Pb}$ phases exist on the surface of soil particles, attrition, in which only the surface is removed from the soil particles, is one of the most effective mechanical methods to remove the $\mathrm{Pb}$ and reduce soil contamination. Although the attrition process also generates wastewater containing $\mathrm{Pb}$ as other physical or chemical remediation technologies, there is little change in physical, chemical and biological nature of the washed soil after the attrition.

Montinaro et $\mathrm{al}^{22)}$ reported that ball milling without any additives could reduce the leachable fraction of cadmium or zinc from contaminated soils. Orumwense ${ }^{23)}$ and Schaaff et $a{ }^{24)}$ used a stirrer mill with milling media to investigate the application of attrition to metal- and oil-contaminated soil, respectively. In their observations, both attrition and bulk grinding occurred because the milling media had sufficient energy to break the soil particles. Bayley and Biggs $^{25)}$ reported the most appropriate conditions for an attrition scrubber without milling media for treatment of oilcontaminated soil. Although some researchers have evaluated mechanical treatment processes, including attrition, for the treatment of contaminated soil, ${ }^{26-28)}$ the mechanism of attrition and specific effects of various factors on attrition have not been evaluated quantitatively.

The objective of this study was to quantitatively evaluate attrition using an intensive mixer for the treatment of $\mathrm{Pb}$ contaminated soil from shooting ranges. $\mathrm{Pb}$ contaminated soils from two different shooting ranges in Japan were used for this investigation, one of which was sandy and the other was silty. To quantitatively evaluate the effects of attrition, the attrition rate was estimated from the change in the particle size distribution at different grinding times and the liquid/ solid ratio using a population balance approach, which was based on the kinetic theory of abrasion. ${ }^{29,30)}$ The most appropriate conditions for the intensive mixer, including the liquid/solid ratio and grinding time, were determined to 
maximize attrition of $\mathrm{Pb}$ from the contaminated soil. The classic and basic five-step sequential extraction procedure proposed by Tessier et ll $^{31)}$ to determine the speciation of heavy metals in geochemical phases was applied to evaluate the specific effects of attrition on the various forms of $\mathrm{Pb}$ in the contaminated soil.

\section{Experimental Procedure}

\subsection{Soil characterization}

$\mathrm{Pb}$ contaminated soil was collected from two different shooting ranges in Japan. The average sampling depth was $10 \mathrm{~cm}$. The coarsest material $(+2 \mathrm{~mm})$ in the soil sample was screened out before soil characterization or attrition experiments to remove spent pellets or their parts. The soil was then air-dried to a water content of approximately $10 \%$ and divided into samples using the cone and quarter method or a chute riffle. Part of the sample was wet-screened into five fractions, in which the smallest fraction was $<20 \mu \mathrm{m}$. The samples were decomposed in aqua regia and the concentration of $\mathrm{Pb}$ was determined by inductively coupled plasma atomic emission spectrometry (ICP-AES) (SPS-4000, Seiko Instruments, Chiba, Japan; and IRIS-AP, Seiko Instruments, Chiba, Japan). Additionally, the compositions and chemical forms of the samples were measured with X-ray fluorescence (XRF) (PW1480/1404, PANalytical, Tokyo, Japan) and Xray diffraction (XRD) analysis (Geiger flex RAD-IR, Rigaku, Japan).

\subsection{Sequential extraction procedure}

Speciation of $\mathrm{Pb}$ in the two samples was determined using Tessier's procedure. ${ }^{31)}$ Based on the laboratory equipment and operating conditions available, Tessier's method was modified as follows.

(i) Ion exchangeable species: The sample $(0.5 \mathrm{~g})$ was placed in a $15 \mathrm{~mL}$ centrifugal tube. Four milliliters of 1 mol/L NaAc solution was added $(\mathrm{pH} 8)$ and the tube was shaken at room temperature for $1 \mathrm{~h}$. The sample was then centrifuged for $30 \mathrm{~min}$ at $2000 \mathrm{rpm}$, followed by suction filtration through a $0.45 \mu \mathrm{m}$ membrane. The $\mathrm{Pb}$ concentration in filtrate was analyzed by ICP-AES.

(ii) Carbonate species: Four milliliters of $1 \mathrm{~mol} / \mathrm{L} \mathrm{NaAc}$ solution adjusted to $\mathrm{pH} 5$ with acetic acid was added to the residue in the centrifuge tube. The suspension was shaken and extracted at room temperature for $5 \mathrm{~h}$, and then the $\mathrm{Pb}$ concentration in filtrate was analyzed after centrifugal separation and suction filtration as detailed above.

(iii) Oxide bound species: Ten milliliters of $0.04 \mathrm{~mol} / \mathrm{L}$ $\mathrm{NH}_{2} \mathrm{OH} \cdot \mathrm{HCl}$ adjusted to $\mathrm{pH} 2.0$ with $25 \%$ acetic acid solution was added to the residue. The mixture was stirred at hourly intervals with continuous shaking for $6 \mathrm{~h}$ at $95^{\circ} \mathrm{C}$. $\mathrm{The} \mathrm{Pb}$ concentration in filtrate was analyzed after centrifugal separation and suction filtration as detailed above.

(iv) Organic bound species: One and a half milliliters of $0.02 \mathrm{~mol} / \mathrm{L} \mathrm{HNO}_{3}$ and $2.5 \mathrm{~mL}$ of a $30 \% \mathrm{H}_{2} \mathrm{O}_{2}$ aqueous solution adjusted to $\mathrm{pH} 2.0$ were added to the residue. The mixture was stirred at hourly intervals and shaken continuously for $2 \mathrm{~h}$ at $85^{\circ} \mathrm{C}$. Then another $1.5 \mathrm{~mL}$ of $30 \% \mathrm{H}_{2} \mathrm{O}_{2}$ was added and the suspension was stirred and shaken under the same conditions for $3 \mathrm{~h}$. After cooling, $2.5 \mathrm{~mL}$ of $3.2 \mathrm{~mol} / \mathrm{L}$
$\mathrm{NH}_{4} \mathrm{Ac}$ and $0.50 \mathrm{~mL}$ of $1 \mathrm{~mol} / \mathrm{L}^{\mathrm{HNO}_{3}}$ with $7.5 \mathrm{~mL}$ of distilled water were added and the suspension was shaken for $30 \mathrm{~min}$. The $\mathrm{Pb}$ concentration in the filtrate was analyzed after centrifugal separation and suction filtration as detailed above.

(v) Insoluble species: The $\mathrm{Pb}$ contained in the residue was extracted using aqua regia. The $\mathrm{Pb}$ concentration in the filtrate was analyzed after centrifugal separation and suction filtration as detailed above.

\subsection{Leaching test}

A leaching test (Japanese standard leaching test No. 46, JST \#46) was performed with the $>20 \mu \mathrm{m}$ size fraction before and after attrition. In JST \#46, $50 \mathrm{~g}$ of sample and $500 \mathrm{~mL}$ of distilled water were placed in a $1000 \mathrm{~mL}$ polyethylene container and shaken horizontally at $200 \mathrm{rpm}$ with a shaking width of $4 \mathrm{~cm}$ for $6 \mathrm{~h}$. The $\mathrm{Pb}$ concentration in the filtrates was analyzed by ICP-AES after suction filtration through a $0.45 \mu \mathrm{m}$ membrane.

\subsection{Attrition experiments}

An intensive mixer (R02 type, Eirich, Germany) with a total volume of $5 \mathrm{~L}$ was used for all the attrition experiments. The intensive mixer had a mechanical overhead stirrer, which was located eccentrically in the mill pot. Both the stirrer and mill pot were inclined at $30^{\circ}$ from vertical, and the mill pot rotated in the opposite direction to the stirrer. We previously performed a computer simulation for soil particle behavior in the intensive mixer using the discrete element method (DEM). ${ }^{32)}$ DEM simulation results showed that collision in the tangential direction between soil particles was major because soil particles moved in a figure of eight near the stirrer in the intensive mixer. The tangential collision would induce abrasion on the surface of soil particles in the intensive mixer.

In attrition experiments, appropriate quantities of the soil sample and water were added to the mixing vessel so that the total mass of the soil and water equaled $3 \mathrm{~L}$. The liquid/ solid mass ratio and grinding time were adjusted to $0.20-0.30$ and $1-4 \mathrm{~min}$, respectively. Because results from preliminary experiments showed increased rotation speed caused bulk grinding in addition to attrition, the rotational speed was set to the lowest setting for the intensive mixer used in this study (900 rpm).

Soil samples after the grinding experiments were wetscreened into five fractions, followed by $\mathrm{Pb}$ concentration analysis using ICP-AES after decomposition with aqua regia. Sequential extraction by Tessier's procedure (detailed above) was also performed on the soil samples after grinding for each particle size fraction.

All chemical analyses in this study were conducted at least in triplicate and the error was confirmed to be within $1 \%$.

\subsection{Population balance model of abrasion}

The kinetic theory of grinding, which consists of integral and differential equations including the concepts of a particle selection function and a particle breakage function, was reviewed by Austin ${ }^{29)}$ and details of the abrasion model were described by Ouchiyama et al. ${ }^{30)}$ Briefly, in this model the abrasion mechanism is simplified because degradation of a particle occurs at a linear rate relative to the grinding time, 
and a large number of very fine daughter particles are produced. This is given by:

$$
\frac{\partial Q(x, T)}{\partial T}=3 \int_{x}^{1} \frac{g(x, T)}{y} d y+g(x, T)
$$

where $x$ and $y$ are the dimensionless size of a particle and $T$ is the dimensionless grinding time, which is defined as follows:

$$
x=\frac{d}{D_{\max }}, \quad T=\frac{K}{D_{\max }} t,
$$

where $d$ is the particle size, $D_{\max }$ is the maximum size of the particles, $t$ is the grinding time and $K$ is the abrasion rate. The undersize distribution $(Q(x, T)$ in eq. (1)) represents the mass fraction of particles smaller than size $d$, and is expressed as:

$$
Q(x, T)=\int_{0}^{x} g(y, T) d y,
$$

where $g(x, T)$ is the mass frequency size distribution function.

In this study, eqs. (1)-(3) were solved numerically using the trapezoidal method for the integral equation and the finite difference method for the differential equation. The undersize distributions of the soil particles for samples A and B before attrition were used as boundary conditions, $Q(x, 0)$. The undersize distribution at a specific grinding time, $Q(x, T)$, was fit to the observed data after attrition experiments by the least-squares method, with the dimensionless grinding time, $T$, as the fitting parameter. The abrasion rate, $K$, was obtained from the dimensionless grinding time from eq. (2).

\section{Results and Discussions}

\subsection{Soil characterization}

As shown in Fig. 1, the Sample A was a sandy soil and the major particle size fraction was 0.30 to $1.2 \mathrm{~mm}$. Sample B was a silty soil and the major particle size fraction was $<20 \mu \mathrm{m}$. High concentrations of $\mathrm{Pb}$, which exceeded the Japanese regulatory standard $(150 \mathrm{mg} / \mathrm{kg})$, were found in all particle size fractions of both samples. The $\mathrm{Pb}$ concentrations in samples A and B were 6550 and $1489 \mathrm{mg} / \mathrm{kg}$, respectively.

Table 1 shows the mass fraction of each element in samples A and B obtained from XRF analysis. Both samples contained common soil components such as $\mathrm{Si}, \mathrm{Al}$ and $\mathrm{Fe}$, but sample $\mathrm{B}$ contained more minerals, including $\mathrm{K}, \mathrm{Ca}$, $\mathrm{Mg}$ and $\mathrm{Na}$, than sample conducted for each size fraction of the samples. From a XRD analysis, quartz, albite, kaolinite, phlogopite and clinochlore were observed in both samples A and B. Additionally, a clear peak for anorthite was detected for sample $\mathrm{B}$. The $\mathrm{Pb}$ mineral cerrusite was detected in sample $\mathrm{A}$, but no $\mathrm{Pb}$ minerals were detected in sample $\mathrm{B}$. These results show that sample B contains more clay minerals, which resulted in the higher $\mathrm{K}, \mathrm{Ca}, \mathrm{Mg}$ and $\mathrm{Na}$ contents than sample A.

\subsection{Effects of liquid/solid ratio and grinding time}

Figures 2 (sample A) and 3 (sample B) show the undersize distributions of the soil particles before and after attrition, and the mass fraction of $\mathrm{Pb}$ in each size fraction in relation to the overall $\mathrm{Pb}$ content in soil. In these experiments, the grinding time was fixed at $2 \mathrm{~min}$ and the liquid/solid mass ratio was $0.20,0.25$ or 0.30 . The shape of

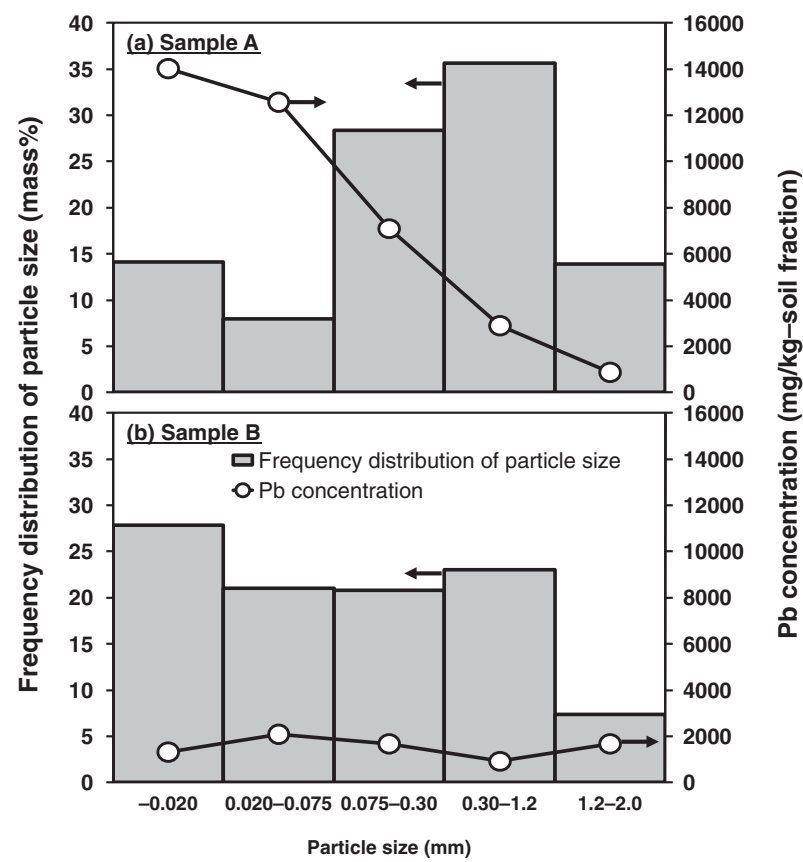

Fig. 1 Frequency distribution of the soil particle size and $\mathrm{Pb}$ concentration in each size fraction. (a) sample A and (b) sample B.

Table 1 Mass fraction of each element in samples A and B determined by $\mathrm{XRF}$ analysis (mass\%).

\begin{tabular}{lccccccccc}
\hline & $\mathrm{Si}$ & $\mathrm{Al}$ & $\mathrm{Fe}$ & $\mathrm{K}$ & $\mathrm{Ca}$ & $\mathrm{Mg}$ & $\mathrm{Ti}$ & $\mathrm{Na}$ & $\mathrm{Mn}$ \\
\hline Sample A & 62.3 & 18.1 & 6.9 & 2.7 & 1.9 & 1.3 & 0.7 & 0.7 & 0.1 \\
Sample B & 56.1 & 15.9 & 9.4 & 7.2 & 3.5 & 1.5 & 1.6 & 1.4 & 0.2 \\
\hline
\end{tabular}
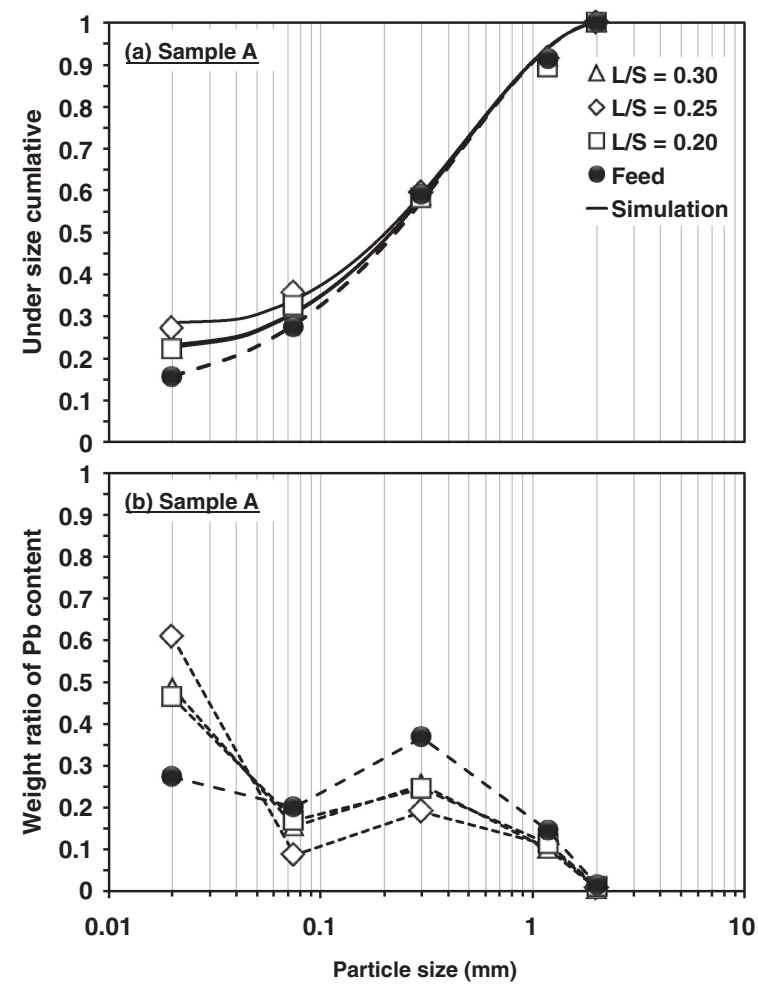

Fig. 2 (a) Undersize distribution of soil particle size and (b) partition ratio of $\mathrm{Pb}$ content for each size fraction before and after attrition for sample A. The solid line was obtained from fitting results from the population balance model. The grinding time was fixed at $2 \mathrm{~min}$ and the liquid/solid mass ratio was $0.20,0.25$ or 0.30 . 

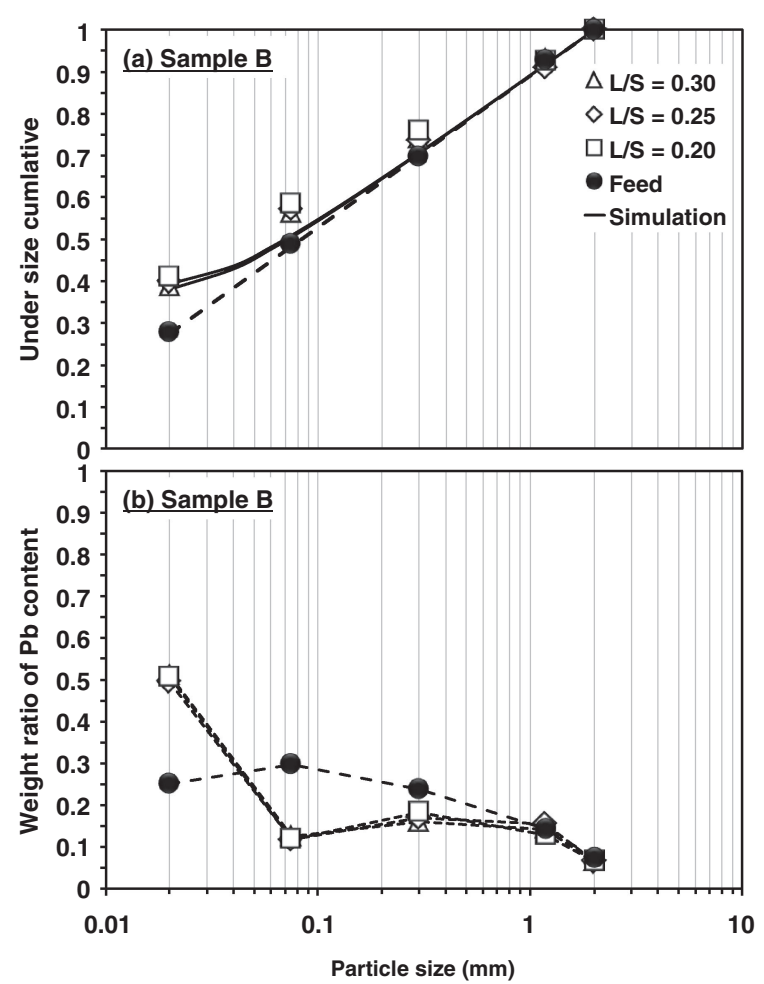

Fig. 3 (a) Undersize distribution of soil particle size and (b) partition ratio of $\mathrm{Pb}$ content in each size fraction before/after attrition experiments for sample B. The solid line was obtained from fitting results from the population balance model. The grinding time was fixed at 2 min and the liquid/solid mass ratio was $0.20,0.25$ or 0.30 .

the particle size distribution barely changed, while the soil mass ratio in the $<20 \mu \mathrm{m}$ of size fraction increased. This means that effective attrition, or grinding of the surface, occurred in the intensive mixer and the coarser soil particles were broken down and had their surface removed and ground into fine particle fractions.

In sample $A$, the most effective attrition was achieved with a liquid/solid mass ratio of 0.25 (Fig. 2). In general, although an appropriate water content is necessary for effective attrition, because the torque is increased by water binding soil particles to each other, too much water reduces the grinding energy from the stirrer and hinders energy propagation to the soil particles. However, soil clump formation was confirmed at a liquid/solid mass ratio of 0.20 in this study. Bayley and Biggs ${ }^{25}$ ) also reported formation of soil clumps when the liquid/solid mass ratio decreased. In sample $\mathrm{B}$, the attrition was not so sensitive to the liquid/solid mass ratio in the range of $0.20-0.30$ (Fig. 3).

Figures 2 and 3 also show the mass fraction of $\mathrm{Pb}$ in each particle size relative to the overall $\mathrm{Pb}$ content in the soil. Compared to before attrition, the $\mathrm{Pb}$ mass fraction increased after attrition in the finest size fraction $(<20 \mu \mathrm{m})$ but decreased in the other size fractions. In sample $\mathrm{A}$, the largest increase (2.3 times) in the mass fraction of $\mathrm{Pb}$ after attrition compared to before attrition in the $<20 \mu \mathrm{m}$ size fraction was with a liquid/solid mass ratio of 0.25 . This corresponds to the liquid/solid mass ratio that produced the most effective abrasion. These results show that attrition was effective for $\mathrm{Pb}$ removal from coarse soil particles, and that $\mathrm{Pb}$ enrichment occurred in fine soil particles. In sample $\mathrm{B}$, the $\mathrm{Pb}$ removal
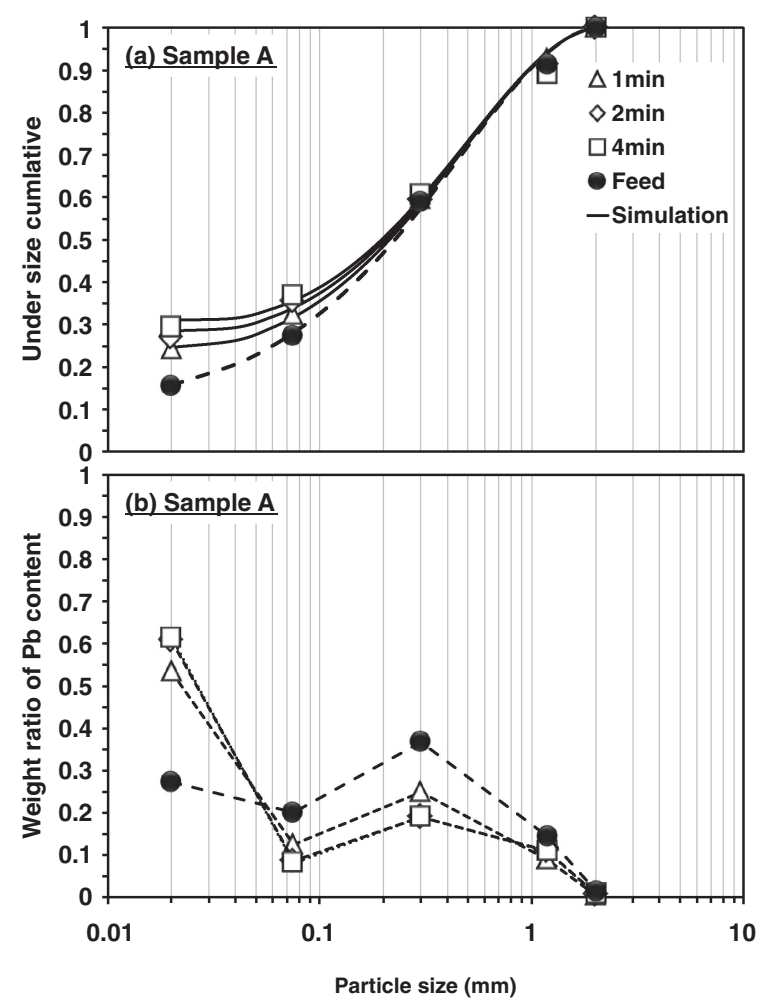

Fig. 4 (a) Undersize distribution of soil particles and (b) partition ratio of $\mathrm{Pb}$ content in each size fraction before and after attrition for sample A. The solid line was obtained from fitting results from the population balance model. The liquid/solid ratio was fixed at 0.25 and the grinding time was 1,2 or $4 \mathrm{~min}$.

from coarse soil particles and $\mathrm{Pb}$ enrichment in fine soil particles were not so sensitive to the liquid/solid mass ratio. The $\mathrm{Pb}$ mass fraction in the $<20 \mu \mathrm{m}$ particle size fraction was 2.0 times more concentrated after attrition than before attrition with all liquid/solid mass ratios. This occurred because the attrition in sample B was not sensitive to the liquid/solid mass ratio.

Figures 4 (sample A) and 5 (sample B) also show the undersize distribution and the mass fraction of $\mathrm{Pb}$ relative to the overall $\mathrm{Pb}$ content in the soil at various grinding times. In these experiments, the liquid/solid mass ratio was fixed at 0.25 and grinding time was 1,2 or $4 \mathrm{~min}$. In sample A, the undersize distribution shows that abrasion advanced rapidly until $1 \mathrm{~min}$, and this was followed by slow abrasion until $4 \mathrm{~min}$. In sample B, abrasion was almost complete at $1 \mathrm{~min}$, and further abrasion was minimal after this. Although the specific reason for these differences between samples $A$ and B is unknown, the soil particles in sample B would have a thinner soft layer on their surface and a harder core than those sample A.

\subsection{Quantitative evaluation of attrition for $\mathrm{Pb}$ removal}

Figures 2-5 also show the simulation results (solid line) using the population balance model of abrasion described by eqs. (1)-(3), where the dimensionless grinding time, $T$, was treated as a fitting parameter to the experimental results. Good agreement between the experimental and simulation results was achieved, especially for sample A. The dimensionless grinding time obtained from the fitting procedure and the abrasion time, $K$, calculated from eq. (2) with 

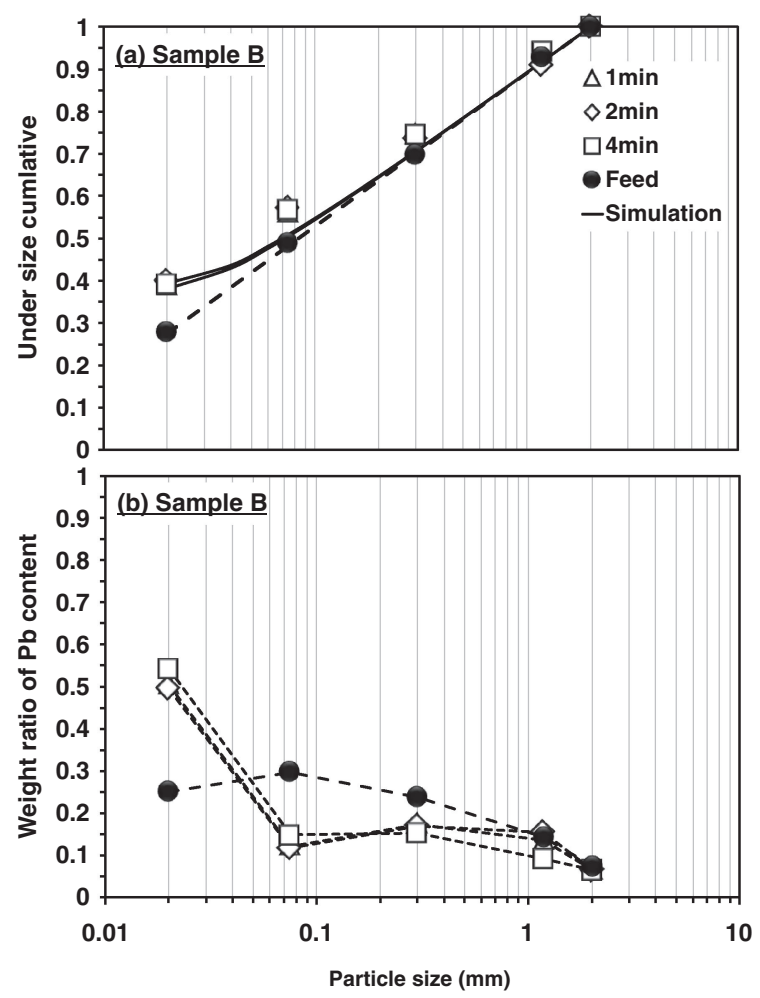

Fig. 5 (a) Undersize distribution of soil particles and (b) partition ratio of $\mathrm{Pb}$ content in each size fraction before and after attrition for sample $\mathrm{B}$. The solid line was obtained from fitting results from the population balance model. The liquid/solid ratio was fixed at 0.25 and the grinding time was 1, 2 or 4 min.

Table 2 Dimensionless grinding time and abrasion rate obtained by the fitting procedure using the size distribution of soil particles before and after attrition and the population balance model.

\begin{tabular}{|c|c|c|c|}
\hline \multirow{2}{*}{$\begin{array}{l}\text { Liquid/solid } \\
\text { mass ratio }\end{array}$} & $\begin{array}{l}\text { Grinding } \\
\text { time }\end{array}$ & $\begin{array}{c}\text { Dimensionless } \\
\text { time }\end{array}$ & Abrasion rate \\
\hline & $t(\min )$ & $T$ & $K(\mu \mathrm{m} / \mathrm{s})$ \\
\hline \multicolumn{4}{|l|}{ Sample A } \\
\hline 0.25 & 1 & 0.0014 & 0.047 \\
\hline 0.25 & 2 & 0.0019 & 0.032 \\
\hline 0.25 & 4 & 0.0022 & 0.018 \\
\hline 0.20 & 2 & 0.0011 & 0.018 \\
\hline 0.30 & 2 & 0.0012 & 0.020 \\
\hline \multicolumn{4}{|l|}{ Sample B } \\
\hline 0.25 & 1 & 0.0014 & 0.047 \\
\hline 0.25 & 2 & 0.0016 & 0.027 \\
\hline 0.25 & 4 & 0.0015 & 0.013 \\
\hline 0.20 & 2 & 0.0014 & 0.027 \\
\hline 0.30 & 2 & 0.0016 & 0.023 \\
\hline
\end{tabular}

$D_{\max }=2 \mathrm{~mm}$, are shown in Table 2 . The abrasion rate shown in Table 2 is the average value obtained over the grinding time. The largest abrasion rate $(0.047 \mu \mathrm{m} / \mathrm{s})$ was obtained after $1 \mathrm{~min}$ of the grinding in both samples A and B. After this time the abrasion rate decreased drastically as the grinding time increased. The abrasion rate after 2 or $4 \mathrm{~min}$ of grinding in sample B was smaller than that in sample A.
Table 3 Leached $\mathrm{Pb}$ concentration from the $>20 \mu \mathrm{m}$ particle size fraction determined by the Japanese standard leaching test (No. 46) before and after attrition. The liquid/solid ratio was 0.25 and the grinding time was $2 \mathrm{~min}$.

\begin{tabular}{ccc}
\hline \multirow{2}{*}{ Sample } & \multicolumn{2}{c}{ Leached $\mathrm{Pb}$ concentration $(\mathrm{mg} / \mathrm{L})$} \\
\cline { 2 - 3 } & Before attrition & After attrition \\
\hline A & 0.57 & 0.24 \\
B & 0.11 & N.D. \\
\hline
\end{tabular}

These results show that the soil particles in sample B have a thinner soft layer on the surface and a harder core than those in sample A. The size distribution of the soil particles would not be as sensitive to attrition because the same abrasion rate was observed in the early stages of attrition for both samples of $\mathrm{A}$ and $\mathrm{B}$.

Figures 2-5 show the mass fraction of $\mathrm{Pb}$ in the $>20 \mu \mathrm{m}$ particle size fraction decreased in both samples A and B. However, it still did not meet Japanese regulatory standards for the $\mathrm{Pb}$ concentration in soil $(150 \mathrm{mg} / \mathrm{kg})$ because both samples originally had considerably high $\mathrm{Pb}$ contents $(6550 \mathrm{mg} / \mathrm{kg}$ for sample A, $1489 \mathrm{mg} / \mathrm{kg}$ for sample B). However, the $>20 \mu \mathrm{m}$ particle size fraction in sample B was within the Japanese regulatory standard for $\mathrm{Pb}$ leached concentration $(0.01 \mathrm{mg} / \mathrm{L})$ after attrition. The results from the leaching test (JST \#46) in the $>20 \mu \mathrm{m}$ particle size fraction before and after attrition are shown in Table 3. The attrition conditions were a liquid/solid mass ratio of 0.25 and grinding time of $2 \mathrm{~min}$. After attrition in the intensive mixer, the concentration of leached $\mathrm{Pb}$ in sample $\mathrm{A}$ decreased by almost a half and that in sample B decreased below measurable limits. These results suggested that the leachable $\mathrm{Pb}$ content was concentrated in the soft layer on the surface of the soil particles, and that the core of the soil particles in sample B was harder that in sample A.

Figure 6 shows that the relationship between the abrasion thickness and incremental changes in the mass faction of $\mathrm{Pb}$ the $<20 \mu \mathrm{m}$ particle size fraction. The abrasion thickness was calculated from the abrasion rate, $K$, multiplied by the grinding time, $t$. The incremental changes in the mass faction of $\mathrm{Pb}$ were calculated from the incremental changes in the mass of $\mathrm{Pb}$ divided by the total mass of $\mathrm{Pb}$ in the soil. The mass fraction of $\mathrm{Pb}$ in the $<20 \mu \mathrm{m}$ particle size fraction increased roughly in proportion to the abrasion rate. Interestingly, the ratio of $\mathrm{Pb}$ enrichment in the $<20 \mu \mathrm{m}$ particle size fraction per unit of abrasion thickness was $0.098 \mu^{-1}$ (dashed line in Fig. 4), and this was similar for samples A and B. This result suggests the mass fraction of $\mathrm{Pb}$ contained in the soft layer on the surface of the soil particles is similar in the two samples. In sample A, the mass fraction of $\mathrm{Pb}$ in the $<20 \mu \mathrm{m}$ particle size fraction increased in proportion to the abrasion rate until an abrasion thickness of $4 \mu \mathrm{m}$, but further abrasion over $4 \mu \mathrm{m}$ did not cause further $\mathrm{Pb}$ enrichment. In sample $\mathrm{B}, \mathrm{Pb}$ enrichment was almost complete by an abrasion thickness of about $3 \mu \mathrm{m}$, and further abrasion did not occur with these samples. As suggested by earlier results, this result indicates that the soil particles in sample B have a thinner soft layer and a harder core than those in sample A. 


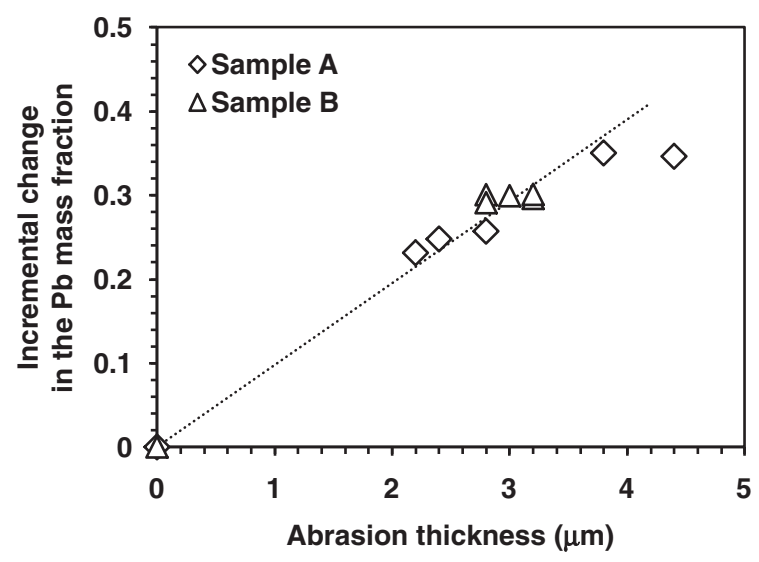

Fig. 6 Relationship between the abrasion thickness from the surface of the soil particles and incremental change in the mass fraction of $\mathrm{Pb}$ in the $<20 \mu \mathrm{m}$ particle size fraction.

\subsection{Effect of $\mathrm{Pb}$ speciation}

Sequential extraction by Tessier's procedure was used to determine the $\mathrm{Pb}$ speciation in the $>20 \mu \mathrm{m}$ particle size fraction before and after attrition for both samples A and B (Fig. 5). In these experiments, the attrition conditions were a liquid/solid mass ratio of 0.25 and grinding time of $2 \mathrm{~min}$. Several researchers have reported the $\mathrm{Pb}$ speciation in contaminated soil from shooting ranges. Cao et al. analyzed the weathered soil of a shooting range with XRD to confirm the presence of $\mathrm{Pb}$ carbonates such as hydrocerussite $\left(\mathrm{Pb}_{3}\left(\mathrm{CO}_{3}\right)_{2}(\mathrm{OH})_{2}\right)$ and cerussite $\left.\left(\mathrm{PbCO}_{3}\right) .{ }^{9}\right)$ More recent investigations with $\mathrm{X}$-ray absorption fine structure spectroscopy have revealed the presence of $\mathrm{Pb}$ sorbed with organic matter and $\mathrm{Fe}$ or $\mathrm{Mn}$ oxide minerals in the weathered soils from a shooting range. ${ }^{20)}$ In this study, high concentrations of $\mathrm{Pb}$ carbonate species (form (ii)), oxide bound species (form (iii)) and organic bound species (form (iv)) were found in samples A and B before attrition. In sample B, the concentration of insoluble $\mathrm{Pb}$ species (form (v)) was also high because the soil particles in sample B were more silty and harder than those in sample A.

In Fig. 7, the $y$-axis shows the mass fraction of $\mathrm{Pb}$ in the $>20 \mu \mathrm{m}$ particle size fraction relative to the total $\mathrm{Pb}$ content of the soil. After attrition, the $\mathrm{Pb}$ concentration in the $>20 \mu \mathrm{m}$ particle size fraction decreased in samples A and B because of $\mathrm{Pb}$ removal from this size fraction and $\mathrm{Pb}$ enrichment in the $<20 \mu \mathrm{m}$ particle size fraction. Figure 5 shows that the $\mathrm{Pb}$ concentration decreased particularly in oxide or organic bound species and carbonates species in samples A and B. Consequently, these species were the major chemical forms of $\mathrm{Pb}$ in the soft layer on the surface of the soil particles, which corresponds to the major forms found in the weathered soil. Therefore, attrition would be an effective method for treatment of weathered soil containing $\mathrm{Pb}$ carbonates or other oxide or organic bound species.

\section{Conclusion}

The effects of attrition on sandy and silty $\mathrm{Pb}$-contaminated soil from shooting ranges were investigated. After attrition in the intensive mixer, the concentration of leached $\mathrm{Pb}$ in sandy soil decreased by almost a half and that in silty soil decreased

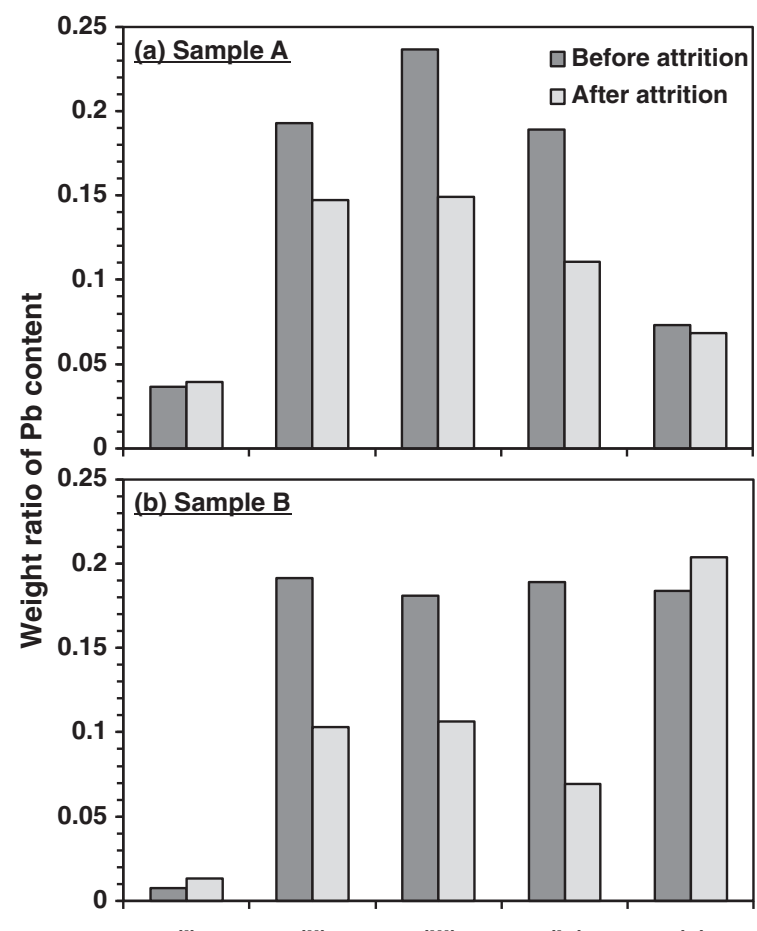

(i)

(ii)

(iii)

(iv)

(v)

Fig. $7 \mathrm{~Pb}$ speciation obtained by sequential extraction following Tessier's procedure before and after attrition in the $>20 \mu \mathrm{m}$ size fraction. Species (i) -(v) are (i) ion exchangeable species, (ii) carbonates species, (iii) oxides bound species, (iv) organic bound species, and (v) insoluble species. The liquid/solid ratio was 0.25 and the grinding time was 2 min. (a) sample A and (b) sample B.

below measurable limits. These results suggested that the leachable $\mathrm{Pb}$ content was concentrated in the soft layer on the surface of the soil particles. Sequential extraction using Tessier's procedure for the $>20 \mu \mathrm{m}$ size fraction before and after attrition showed the attrition was more effective for the oxides or organic-bound species and carbonate species of $\mathrm{Pb}$ chemical forms.

A quantitative evaluation of the abrasion rate became possible by a population balance model from the size distribution of soil particles before and after attrition. The maximum abrasion rate was $0.047 \mu \mathrm{m} / \mathrm{s}$ in the first stage of attrition ( $1 \mathrm{~min}$ of grinding), and then declined between 2 and $4 \mathrm{~min}$ of grinding. The two samples had similar maximum abrasion rates, but the decline in the abrasion rate was larger in the silty soil, which has a thinner soft layer on the surface of the soil particles, than the sandy soil.

\section{REFERENCES}

1) Water Environment Division, Environmental Management Bureau, MOEJ: Dojo Osen Taisaku Ho No Seko Jyokyo Oyobi Dojo Osen Chosa Taisaku Jirei ni Kansuru Chosa Kekka (in Japanese), (MOEJ, Japan, 2010) pp. 11-19.

2) Water Environment Division, Environmental Management Bureau, MOEJ: Dojo Osen Taisaku Ho No Seko Jyokyo Oyobi Dojo Osen Chosa Taisaku Jirei ni Kansuru Chosa Kekka (in Japanese), (MOEJ, Japan, 2010) pp. 34-37.

3) T. Arao, S. Ishikawa, M. Murakami, K. Abe, Y. Maejima and T. Makino: Paddy Water Environ. 8 (2010) 247-257.

4) D. I. Bannon, J. W. Drexler, G. M. Fent, S. W. Casteel, P. J. Hunter, W. J. Brattin and M. A. Major: Environ. Sci. Technol. 43 (2009) 90719076 . 
5) M. Niinae, K. Nishigaki and K. Aoki: Mater. Trans. 49 (2008) $2377-$ 2382 .

6) H. S. Jung, S. T. Yun, B. Y. Choi, H. M. Kim, M. Jung, S. O. Kim and K. H. Kim: J. Soil. Sed. 10 (2010) 1142-1158.

7) V. Chrastný, M. Komárek and T. Hájek: Environ. Monit. Assess. 162 (2010) 37-46.

8) Y. Hashimoto, T. Taki and T. Sato: J. Environ. Manag. 90 (2009) 1782 1789.

9) X. Cao, L. Q. Ma, M. Chen, D. W. Hardison and W. G. Harris: J. Environ. Qual. 32 (2003) 526-534.

10) B. Louriño-Cabanaa, L. Lesvena, A. Charriaua, G. Billona, B. Ouddanea and A. Boughrietb: J. Hazard. Mater. 186 (2011) 2129 2137.

11) G. A. K. Koyashiki, M. M. B. Paoliello and P. B. Tchounwou: Rev. Environ. Health. 25 (2010) 243-253.

12) M. E. Finster, K. A. Gray and H. J. Binns: Sci. Total Environ. 320 (2004) 245-257.

13) J. A. Ryan, K. G. Scheckel, W. R. Berti, S. L. Brown, S. W. Casteel, R. L. Chaney, J. Hallfrisch, M. Doolan, P. Grevatt, M. Maddaloni and D. Mosby: Environ. Sci. Technol. 38 (2004) 18A-24A.

14) T. Nakade, Y. Tomura, K. Jin, H. Taniyama, M. Yamamoto, A. Kikkawa, K. Miyagi, E. Uchida, M. Asakawa, T. Mukai, M. Shirasawa and M. Yamaguchi: J. Wildl. Dis. 41 (2005) 253-256.

15) W. N. Beyer, D. J. Audet, A. Morton, J. K. Campbell and L. LeCaptain: J. Environ. Qual. 27 (1998) 1533-1538.

16) G. Dermont, M. Bergeron, G. Mercier and M. Richer-Laflèche: J. Hazard. Mater. 152 (2008) 1-31.
17) A. Jankaite and S. Vasarevičius: J. Environ. Eng. Landsc. Manag. 13 (2005) 109a-113a.

18) R. A. Griffiths: J. Hazard. Mater. 40 (1995) 175-189.

19) J. Ducaroir and I. Lamy: Anal. 120 (1995) 741-745.

20) Y. Hashimoto, H. Matsufuru, M. Takaoka, H. Tanida and T. Sato: J. Environ. Qual. 38 (2009) 1420-1428.

21) Y. Hashimoto, N. Yamaguchi, M. Takaoka and K. Shiota: Sci. Total Environ. 409 (2011) 1001-1007.

22) S. Montinaro, A. Concas, M. Pisu and G. Cao: Chem. Eng. J. 142 (2008) 271-284.

23) A. O. Orumwense: Miner. Metall. Process. 23 (2006) 40-44.

24) F. Schaaff, M. Schneider and T. Neeße: Int. J. Miner. Process. 74 (2004) S291-S298.

25) R. W. Bayley and C. A. Biggs: Chem. Eng. J. 111 (2005) 71-79.

26) M. Fend, L. Lorenzen, C. Aldrich and P. W. Marè: Miner. Eng. 14 (2001) 1093-1100.

27) G. Mercier, J. Duchesne and D. Blackburn: J. Environ. Eng. 127 (2001) $348-358$.

28) M. A. Marino, R. M. Brica and C. N. Neale: Environ. Prog. 16 (1997) 208-214.

29) L. G. Austin: Powder Technol. 5 (1971/1972) 1-17.

30) N. Ouchiyama, S. L. Rough and J. A. Bridgwater: Chem. Eng. Sci. 60 (2005) 1429-1440

31) A. Tessier, P. G. C. Campbell and M. Bisson: Anal. Chem. 51 (1979) $844-851$.

32) C. Tokoro, T. Yamashita, H. Kubota and S. Owada: Resour. Recycl. 56 (2009) 113-119. 